\title{
Determining the Effect of Adding Greenhouse Structure to a Residential Building Using Friction Pendulum System (FPS) under Near-Field Earthquakes
}

\author{
Ali Vatanshenas ${ }^{1} \&$ Behnam Tavakoli Moghadam ${ }^{2}$ \\ ${ }^{1}$ MSc in Earthquake Engineering, Engineering Faculty, Islamic Azad University Central Tehran Branch, Tehran, \\ Iran \\ ${ }^{2}$ Earthquake Engineering MSc student, Engineering Faculty, Islamic Azad University Central Tehran Branch, \\ Tehran, Iran \\ Correspondence: Ali Vatanshenas, MSc in Earthquake Engineering, Engineering Faculty, Islamic Azad \\ University Central Tehran Branch, Tehran, Iran. E-mail: a.vatanshenas@gmail.com
}

\author{
Received: April 11, 2018 \\ Accepted: April 25, 2018 \\ Online Published: May 11, 2018 \\ doi:10.5539/eer.v8n1p56 \\ URL: https://doi.org/10.5539/eer.v8n1p56
}

\begin{abstract}
Adding greenhouse structures to existing residential structures in order to increase agricultural products is considered as a challenge. In this paper the comparison of a three-dimensional residential building is investigated in three cases: without greenhouse structure, with rigid connection to the greenhouse structure and the greenhouse structure seismically isolated from the base structure using FPS. It was observed that adding additional mass on the last floor of the base structure can cause an unpredictable increase in the amounts of base shear and roof displacement. It was observed that FPS showed a proper behavior during near-field earthquakes. In terms of base shear and roof displacement the structure with FPS showed a better performance than the structure without FPS.
\end{abstract}

Keywords: environmental engineering, friction pendulum system, near-field earthquakes

\section{Introduction}

Due to the massive increase in the world population during the past recent centuries, the importance of providing enough agricultural products is undeniable to human beings. So building safe and economical greenhouse structures are concerned more recently. Greenhouse structures are usually built outside of the big cities and where sunlight can be obtained during different seasons of the year. The distance between where the agricultural products are made and where these products will be consumed can cause expensive distribution costs and in some cases the products will lose their adequate quality because of the time wasted for transportation. This problem could get significantly improved if the locations that products are made and used were in the cities. This idea is possible if greenhouse structures could be installed on the roof of the existing structures. The idea of adding greenhouse structures to the existing buildings is not a new concept. But it seems that the effect of this extra mass to the base structure during an earthquake is neglected. Basically adding extra mass to the existing structure cause an increase in the energy entered to the structure. But in some cases like using pendulum tuned mass dampers, the additional mass improves the behavior of the basic building and decreases the vibration of the structure (Vatanshenas, 2017).

During the past few decades, researchers have understood the importance of near-field earthquakes and investigated the effect of near-field earthquakes to the structures. The first investigations about this phenomenon started when Kern County earthquake (1952) occurred (Cox \& Ashford, 2002). Near-field earthquakes cause an increase in the response of the structures (Bertero \& etal, 1978). Near-field earthquakes have rich frequency contents and despite the far-field earthquakes higher frequencies exist in the records (Ghobarah, 2004).

\section{Friction Pendulum System Characteristics}

Friction pendulum isolators are one of the most popular sliding isolators. In this type of the isolators the kinetic motion and the friction force are combined with each other. Seismic responses of the isolated structures are dependent to the mechanical characteristics of the isolators (Dicleli, 2002). Friction pendulum isolators are made 
out of a housing plate, a slider and a concave dish (Figure1). According to equation (1) period of the superstructure $(\mathrm{T})$ only depends on the radius of the concave dish $(\mathrm{R})$ and the gravity acceleration $(\mathrm{g})$ which is assumed to be a constant value of $9.81 \mathrm{~m} / \mathrm{s}^{2}$ (Naeim \& Kelly, 1999). The friction coefficient is obtained from equation (2) (Tsopelas \& etal, 1996). In this equation $\mu$ is the friction coefficient, $\mathrm{f}_{\max }$ is the maximum friction coefficient, $\mathrm{D}_{\mathrm{f}}$ is the difference between the maximum and the minimum friction coefficients, $a$ is the rate parameter and $\dot{u}$ is the velocity. The FPS used in this study has the radius of 1 meter, rate parameter of $50 \mathrm{sec} / \mathrm{m}$, maximum and minimum friction coefficients of 0.08 and 0.03 respectively.

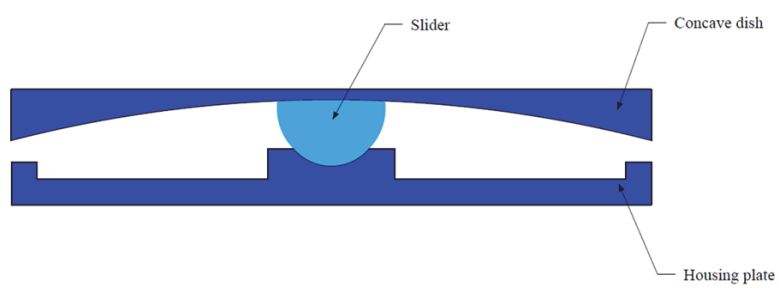

Figure 1. FPS isolator Components

$$
\begin{gathered}
T=2 \Pi \sqrt{ }(R / g) \\
\mu=f_{\text {max }}-D_{f} e^{\left(-\left.a\right|_{u} \mid\right)}
\end{gathered}
$$

\section{Verification}

The structure used for verification is a three-dimensional four-story reinforced concrete structure where FPS isolators are located at the end of columns of its first floor (Figure 2). The floors consist of a slab in 40 centimeters thickness. The height of the first floor is 3 meters and the other floors, is 3.5 meters. The first floor columns have dimensions of 80x80 cm and columns of other floors $70 \times 70 \mathrm{~cm}$ and all beams are 40x70 cm. The considered structure has 8-meter span along the $\mathrm{X}$ axis and two 8-meter spans along the $\mathrm{Y}$ axis. The seismic weight of each floor is also considered to be $1 \mathrm{ton} / \mathrm{m}^{2}$. The Isolator type used in the studied structure is a single-friction pendulum bearing, which has a radius of 1.5 meters and the rate parameter, is $50 \mathrm{sec} / \mathrm{m}$ and $\left(f_{\max } / f_{\min }\right)$ is equal to 3 (Castaldo, Palazzo, \& Della Vecchia, 2015).

The considered structure was under the influence of L'Aquila earthquake records in all three directions X, Y and Z. The earthquake occurred on 06/04/2009 in the Abruzzo, Italy, with a magnitude of 6.3 Richter and the Normal fault mechanism. The hysteresis diagram was obtained for one of the FPS isolators in the corner of the structure under study using the SAP2000 software (SAP2000) (Figure 3), and compared with Figure 4, which relates to a study that verification has been made by it. As can be seen, no significant difference was observed between these two graphs.

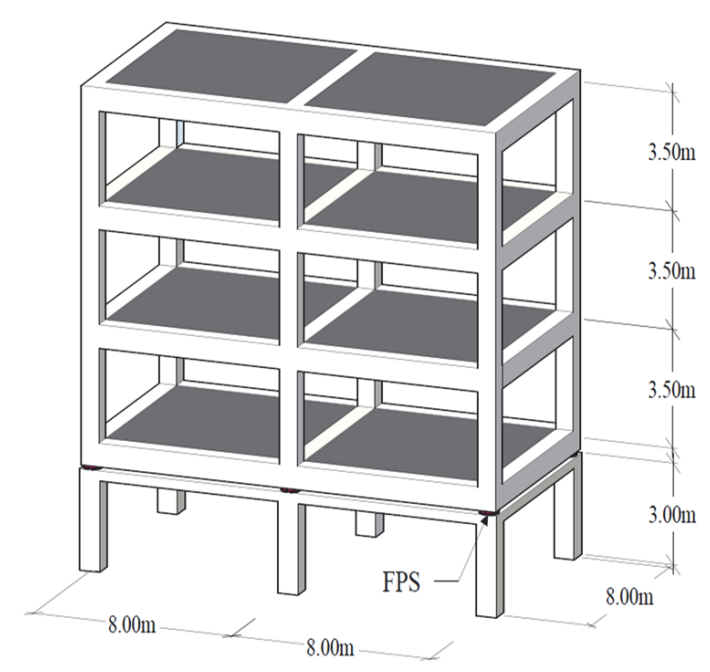

Figure 2. 3D model of the structure isolated by FPS system 


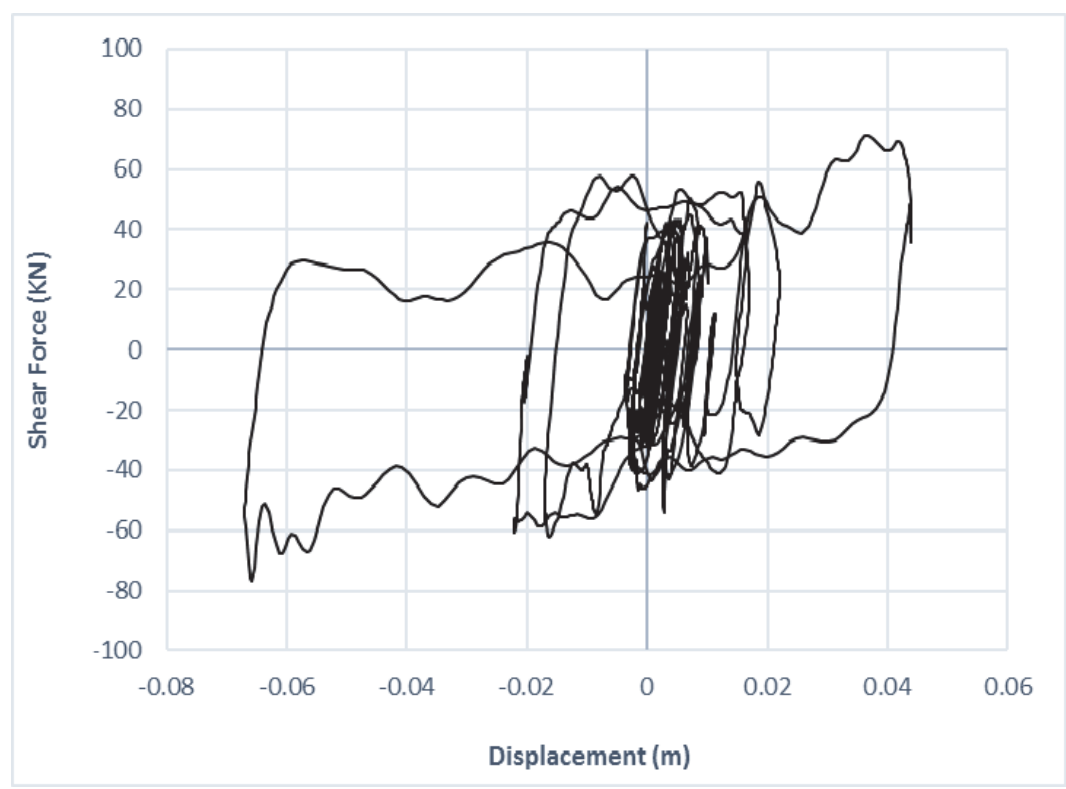

Figure 3. The hysteresis diagram obtained in this study for verification

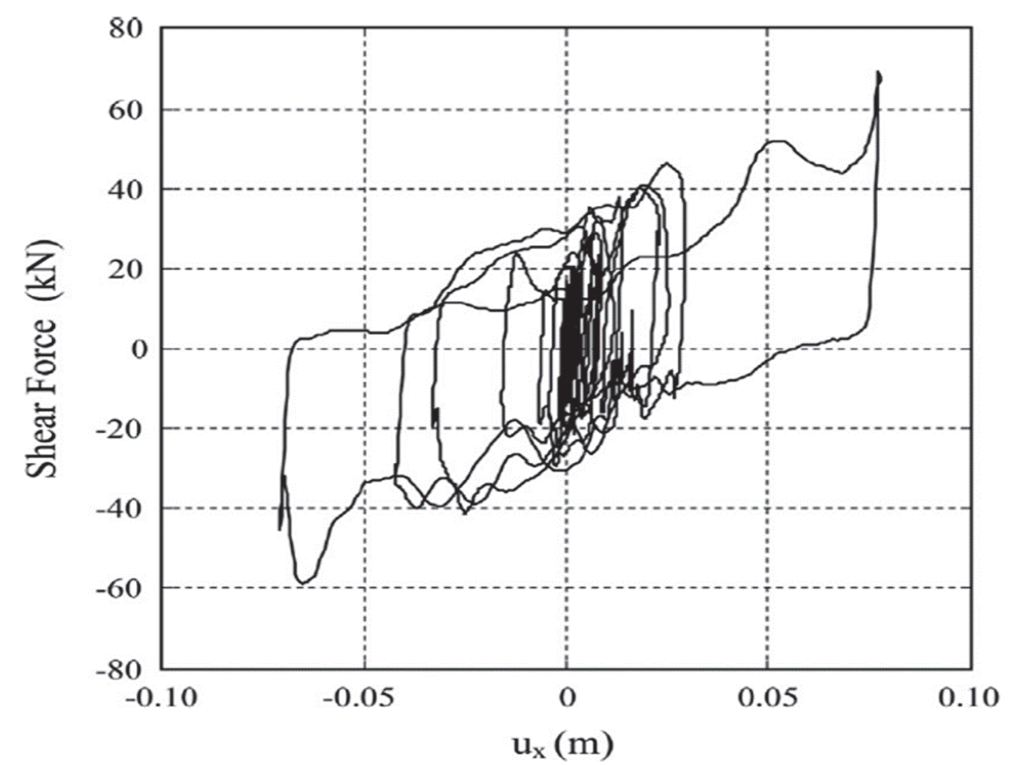

Figure 4 . The hysteresis diagram obtained in the study in which verification is done by it

\section{Modeling and Loading}

In this study a six story steel moment frame residential building is considered as the base structure. This structure has a symmetric plan with three spans of five meters along each horizontal axis. Frame sections used in each floor are represented in Table 1. The dead and live loads on each floor are $4.5 \mathrm{KN} / \mathrm{m}^{2}$ and $2.95 \mathrm{KN} / \mathrm{m}^{2}$ except the last floor which are $5.3 \mathrm{KN} / \mathrm{m}^{2}$ and $1.47 \mathrm{KN} / \mathrm{m}^{2}$ respectively. The near-field earthquake records with similar characteristics such as magnitude, fault mechanism and shear wave velocity are selected as the lateral loads applied to the structure (Table 2). The greenhouse structure with the details shown in (Figure 5) was added to the base structure. The outside of the greenhouse is covered with a light plastic surface and it is assumed that the soil used in the greenhouse has the specific weight of $19.6 \mathrm{KN} / \mathrm{m}^{3}$. In order to determine the effect of additional mass to the base structure two more structures were modeled with the same properties as the base structure plus the additional greenhouse structure, but with different connection types between the base structure and the greenhouse structure. As shown in (Figure 6) three structures are modeled in SAP2000 software (SAP2000). 


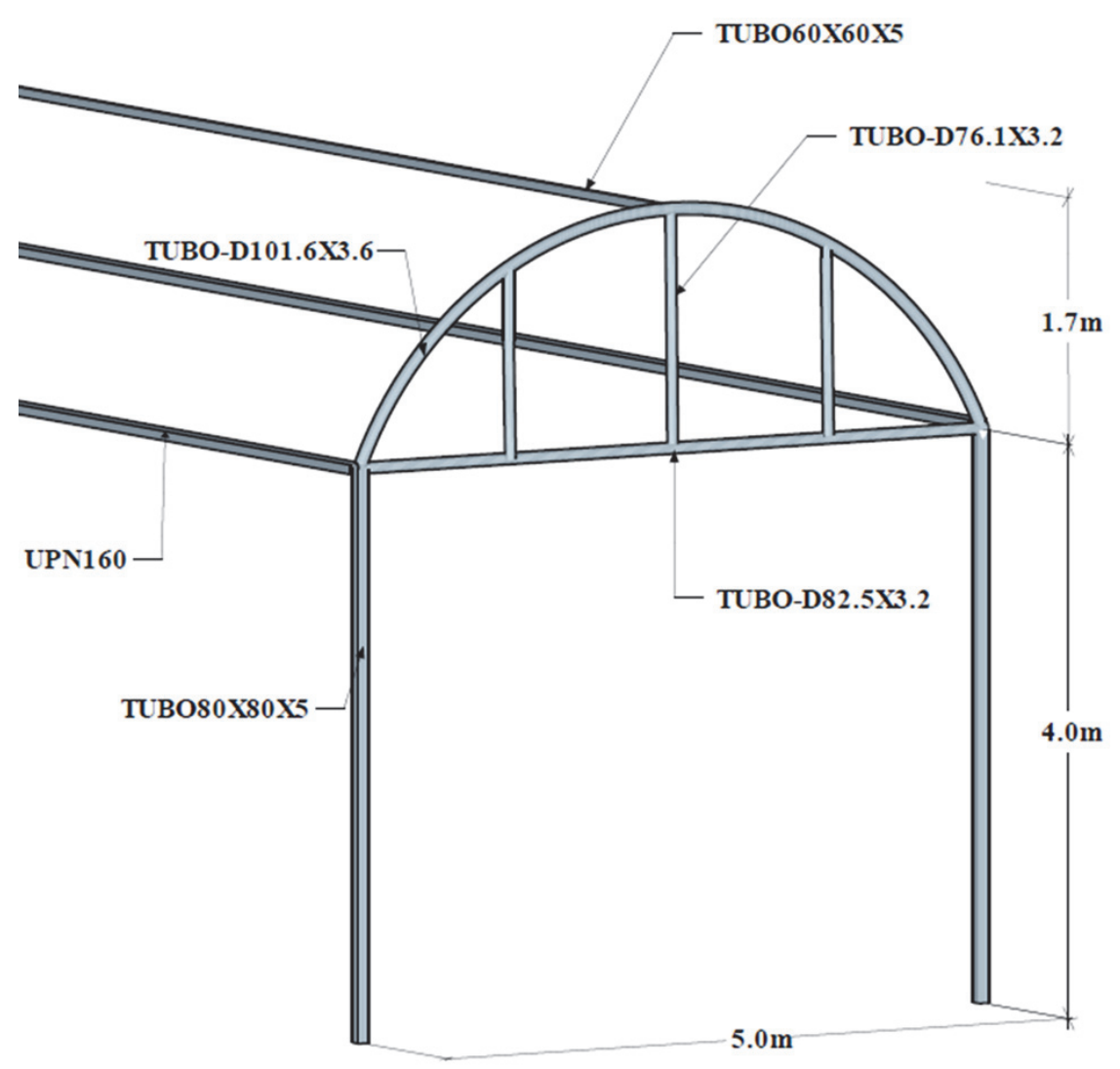

Figure 5. Greenhouse structure with details

Table 1. Frame section elements

\begin{tabular}{ccc}
\hline No. floors & Columns & Beams \\
\hline 1 & TUBO300X300X30 & IPE 400 \\
2 & TUBO300X300X20 & IPE 400 \\
3 & TUBO200X200X30 & IPE 300 \\
4 & TUBO200X200X25 & IPE 300 \\
5 & TUBO200X200X25 & IPE 240 \\
6 & TUBO200X200X20 & IPE 240 \\
\hline
\end{tabular}

Table 2. Selected earthquakes

\begin{tabular}{ccccccc}
\hline Earthquake & Year & Station & Magnitude & Mechanism & $\mathrm{V}_{\mathrm{s}} 30(\mathrm{~m} / \mathrm{s})$ & Scale Factor \\
\hline Manjil & 1990 & Abbar & 7.37 & Strike slip & 723.95 & 0.825 \\
Landers & 1992 & Joshua Tree & 7.28 & Strike slip & 379.32 & 1.498 \\
Duzce & 1999 & Lamont 1061 & 7.14 & Strike slip & 481 & 3.732 \\
Hector Mine & 1999 & Hector & 7.13 & Strike slip & 726 & 1.297 \\
Kobe & 1995 & Nishi-Akashi & 6.9 & Strike slip & 609 & 0.888 \\
Tottori & 2000 & TTR007 & 6.61 & Strike slip & 469.79 & 0.719 \\
Imperial Valley & 1979 & Cerro Prieto & 6.53 & Strike slip & 471.53 & 2.659 \\
\hline
\end{tabular}




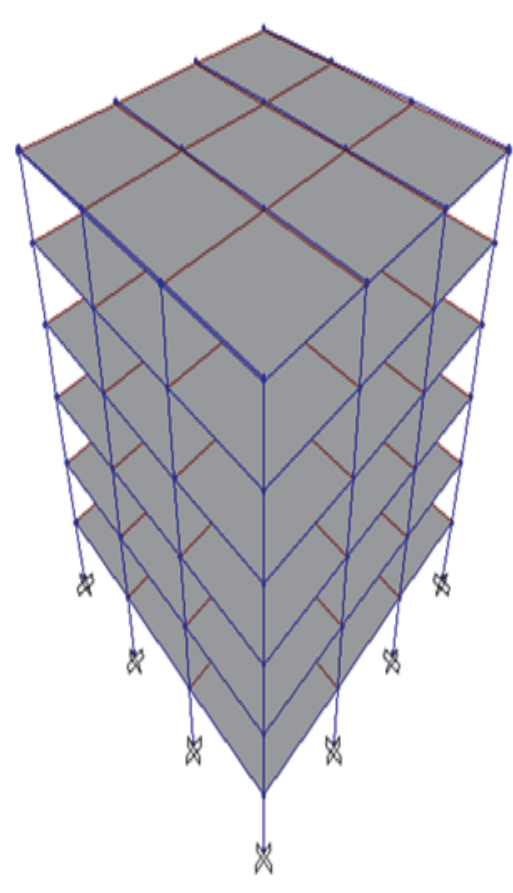

(a)

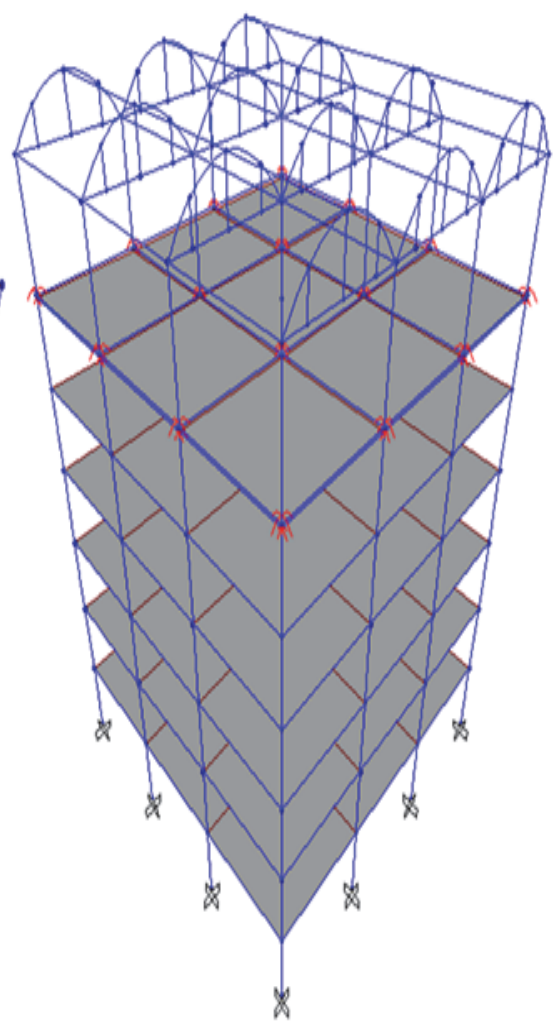

(b)

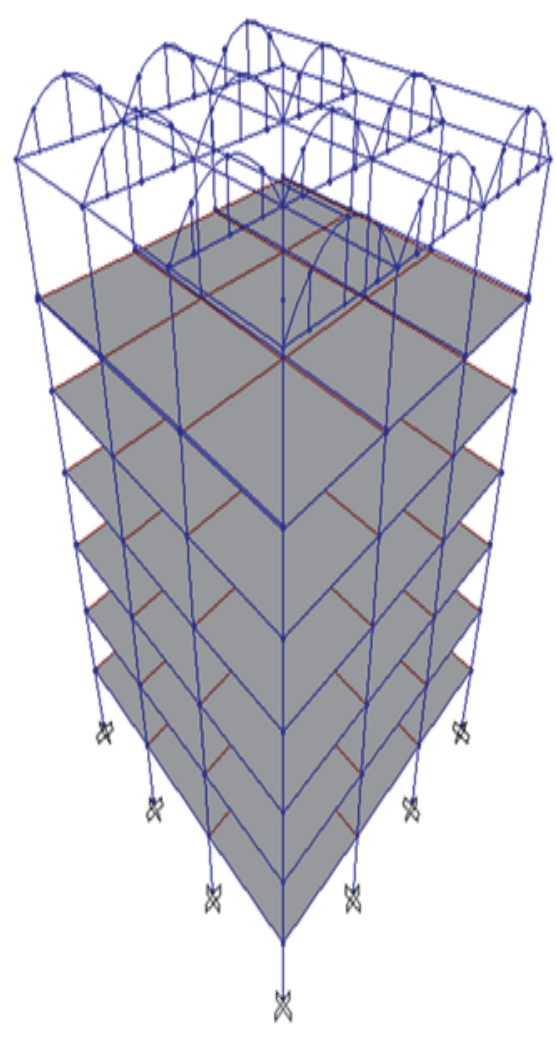

(c)

Figure 6. Base structure (a); Base structure with FPS (b); Base structure without FPS (c)

\section{Determining the Behavior of Base structure with and without Greenhouse Structure}

As shown in Table 3 the period of the first two modes of the base structure, base structure with FPS and without FPS are different which shows that the additional mass and the connection type between the base structure and the greenhouse structure changed the behavior of the base structure. In this study the nonlinear time history analysis is used which is the most accurate and reliable type of analysis among all the other analysis methods. In this study the aforementioned structures were compared to each other based on base shear and roof displacement. It was observed that the behavior of the base structure changed significantly after adding the greenhouse structure. In terms of base shear and roof displacement the results show an erratic and unpredictable behavior of the structure before and after adding the greenhouse structure. But as it is illustrated in Figures 7,8 and Tables 4,5 the base structure with FPS shows more adequate results in both base shear and roof displacement terms. This suitable performance is due to the hysteresis behavior of this friction isolator during ground motions (Figure 9).

Table 3. First two modes of the structures

\begin{tabular}{ccc}
\hline Type of structure & First mode period (s) & Second mode period (s) \\
\hline Base structure & 1.15 & 1.15 \\
Base structure with FPS & 1.81 & 1.79 \\
Base structure without FPS & 1.40 & 1.38 \\
\hline
\end{tabular}




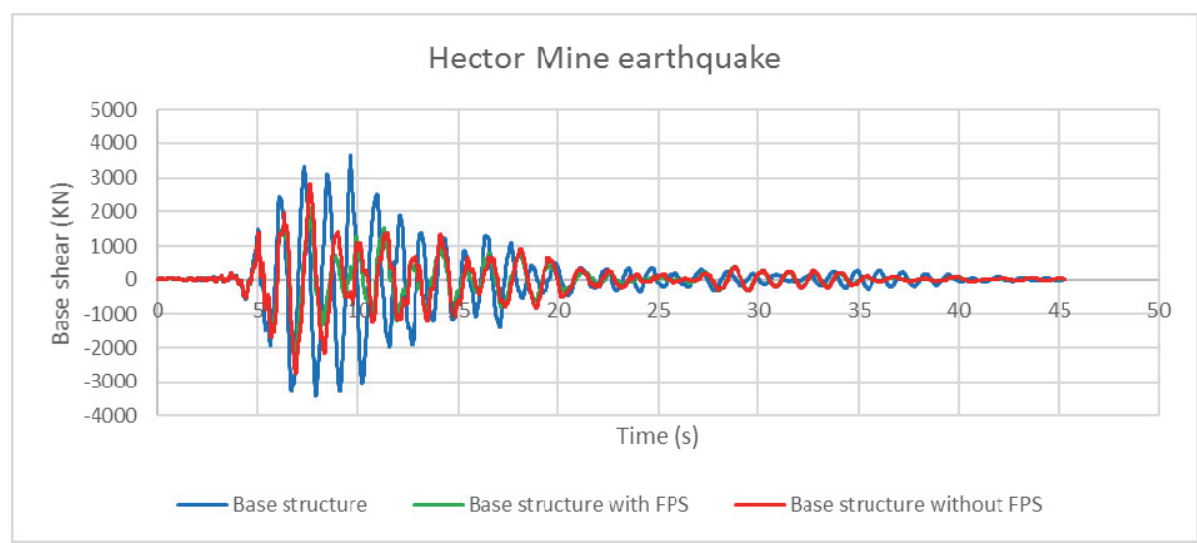

Figure 7. Comparison based on base shear

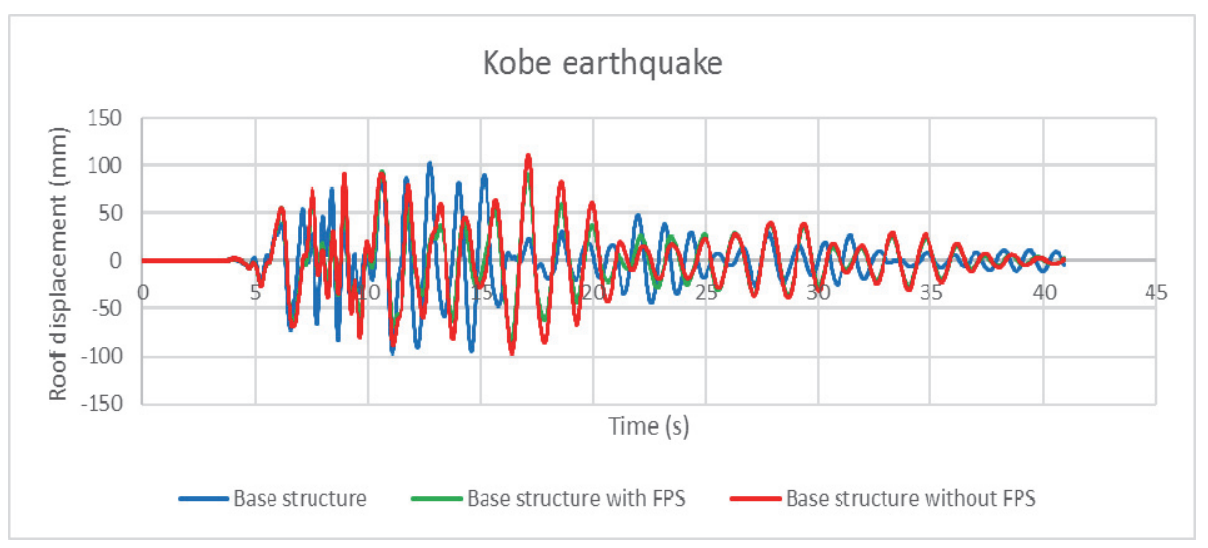

Figure 8. Comparison based on roof displacement

Table 4. Maximum base shear force

\begin{tabular}{cccc}
\hline Earthquake & Base structure (KN) & Base structure with FPS (KN) & Base structure without FPS (KN) \\
\hline Manjil & 1308 & 1392 & 1576 \\
Landers & 4895 & 2477 & 3350 \\
Duzce & 2542 & 1984 & 2544 \\
Hector Mine & 3670 & 2419 & 2835 \\
Kobe & 2291 & 1905 & 2954 \\
Tottori & 1176 & 959.8 & 1113 \\
Imperial Valley & 2804 & 2245 & 3026 \\
\hline
\end{tabular}

Table 5. Maximum roof displacement

\begin{tabular}{cccc}
\hline Earthquake & Base structure $(\mathrm{mm})$ & Base structure with FPS $(\mathrm{mm})$ & Base structure without FPS (mm) \\
\hline Manjil & 64.69 & 88.81 & 105.9 \\
Landers & 374.3 & 196.8 & 258.8 \\
Duzce & 146.8 & 152.7 & 219.4 \\
Hector Mine & 267 & 205.9 & 252.7 \\
Kobe & 102.1 & 93.83 & 111 \\
Tottori & 39.64 & 36.15 & 39.51 \\
Imperial Valley & 185.1 & 124.5 & 185.5 \\
\hline
\end{tabular}




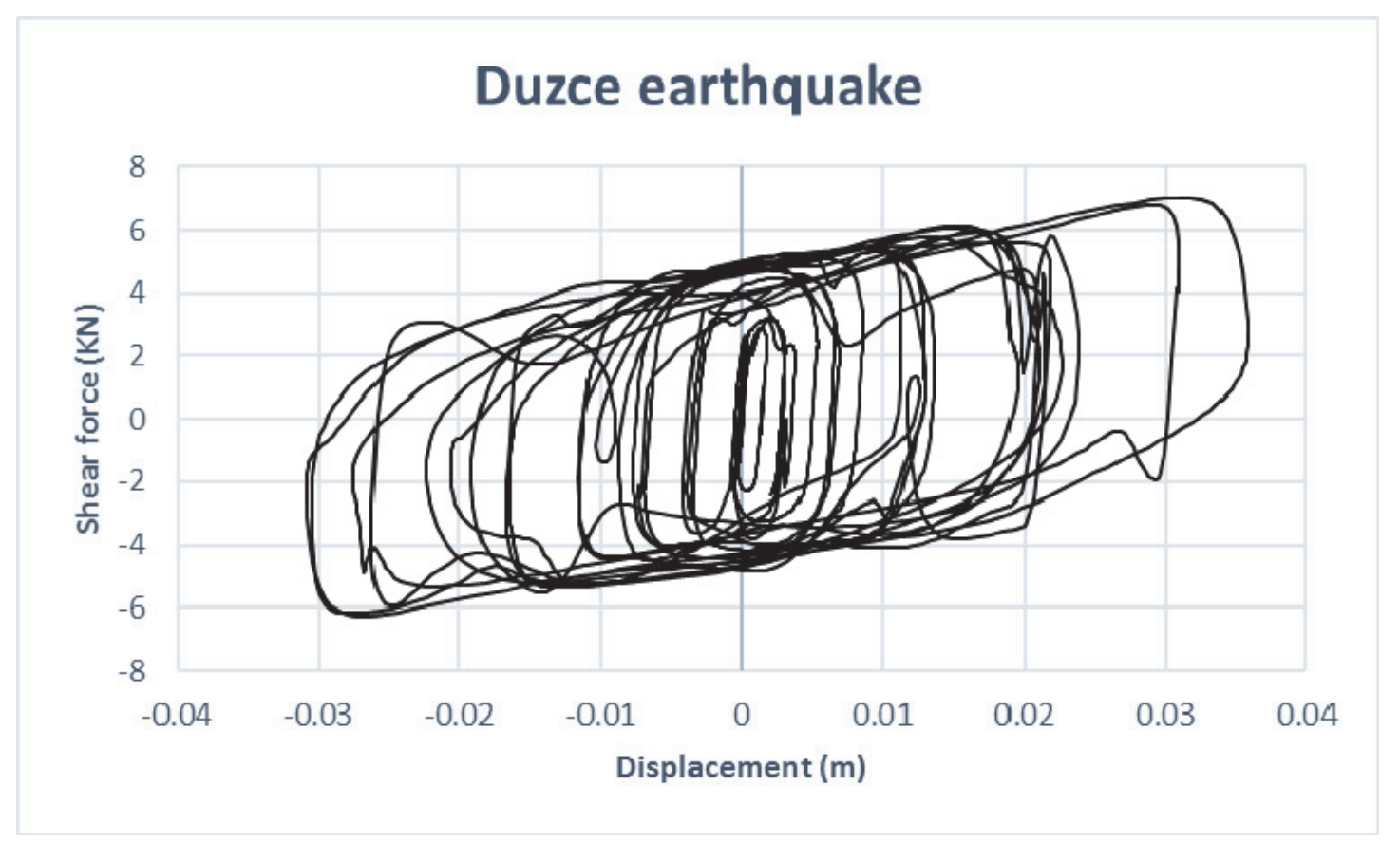

Figure 9. Hysteresis behavior of the FPS during Duzce earthquake

\section{Conclusion}

In conclusion, the additional mass on the last floor of the considered structure had an erratic effect on the base structure. Under some cases the greenhouse structure reduced the base shear and roof displacement and under other cases it increased them. This uncertain behavior shows that the base structure with additional mass on its last floor is dependable on the frequency content of the earthquakes. But it was clear that in terms of base shear and roof displacement the behavior of the base structure with FPS is better than the base structure without FPS. Seismic isolation system absorbed the earthquake energy via its hysteric behavior and caused reduction in the base structure vibration. Based on above observations adding greenhouse structure without considering its effect on the base structure is not recommended. But it is obvious that the base structure with FPS has better performance than the base structure without it.

\section{References}

Bertero, V. V., Mahin, S. A., \& Herrera, R. A. (1978). Aseismic design implications of near-fault san fernando earthquake records, Earthquake engineering \& structural dynamics, 6(1), 31-42. https://doi.org/10.1002/eqe.4290060105

Castaldo, P., Palazzo, B., \& Della Vecchia, P. (2015). Seismic reliability of base-isolated structures with friction pendulum bearings. Eng Struct, 95, 80-93. http://dx.doi.org/10.1016/j.engstruct.2015.03.053

Cox, K. E., \& Ashford, S. A. (2002). Characterization of large velocity pulses for laboratory testing, Pacific Earthquake Engineering Research Center (PEER). Retrieved from https://peer.berkeley.edu/publications/peer_reports/reports_2002/0222.pdf

Dicleli, M. (2002). Seismic design of lifeline bridge using hybrid seismic isolation. Journal of Bridge Engineering, 7(2), 94-103. https://doi.org/10.1061/(ASCE)1084-0702(2002)7:2(94)

Ghobarah, A. (2004). Response of Structures to Near-Fault Ground Motion. 13th World Conference on Earthquake Engineering, no. 1031.

Naeim, F., \& Kelly, J. M. (1999). Design of seismic isolated structures: from theory to practice. John Wiley \& Sons, Inc.

SAP2000. Computers and Structures Inc., Berkley, CA; 2002. 
Tsopelas, P., Constantinou, M. C., Kim, Y. S, \& Okamoto, S. (1996). Experimental study of FPS system in bridge seismic isolation. Earthquake Eng Struct Dyn, 25, 65-78. https://doi.org/10.1002/(SICI)1096-9845(199601)25:1\%3C65::AID-EQE536\%3E3.0.CO;2-A

Vatanshenas, A. (2017). Investigation of PTMD system affected by Parkfield near-field Earthquake. Journal of Modern Applied Science, 11(4), 70-79. http://doi.org/10.5539/mas.v11n4p70

\section{Copyrights}

Copyright for this article is retained by the author(s), with first publication rights granted to the journal.

This is an open-access article distributed under the terms and conditions of the Creative Commons Attribution license (http://creativecommons.org/licenses/by/4.0/). 